\title{
REKAYASA ROUTER UNTUK PENYIMPANAN DATA
}

\author{
Iswan Puji Rahmanto ${ }^{1}$, Anggraini Kusumaningrum² \\ Departemen Informatika \\ Sekolah Tinggi Teknologi Adisutjipto Yogyakarta \\ is1one.fuzzion@gmail.com¹, anggraini@stta.ac.id ${ }^{2}$
}

\begin{abstract}
Data communication is the process by which a resource on a computer can be used by other computers on the condition that the second computer is already connected to a communications network. To connect the computer to the router so the need for different data transfer network will occur. With the process of sharing data on these networks, the delivery process and data storage will be faster and costeffective because it does not require a computer as a storage medium, but a router connected to the storage media. To facilitate the process of sharing data between the two should have an operating system to be easy in the connection process. Differences platform on the operating system being used is not a hindrance so that the computer can be connected. With samba server software and some of the settings on the computer and the router can be mutual sharing of data on the network that is connected to the router.
\end{abstract}

Keywords : router, network, storage media .

\section{Pendahuluan}

Seiring dengan perkembangan teknologi informasi, jaringan komputer saat ini router sangat dibutuhkan untuk menghubungkan berbagai instansi baik di bidang pemerintahan, pendidikan, bahkan di bidang bisnis sekalipun. Dimana harga router yang semakin terjangkau, router semakin banyak jenis dan merknya sehingga konsumen dapat lebih banyak pilihan sesuai kebutuhan yang di inginkan Dalam hal ini router tersebut dimanfaatkan sebagai tempat penyimpanan data seperti hal nya sebuah komputer dengan komponen yang lebih sederhana. Dengan berbagai fasilitas yang dimiliki router, permasalahan pada jaringan komputer dapat diselesaikan serta kinerja router yang direkayasa menyerupai komputer memiliki sistem operasi yang dikhususkan untuk router yang dinamakan dengan Openwrt OS, sehingga router dapat diberi tambahan peralatan memori untuk menyimpan data.

\section{Metode Penelitian}

\subsection{Jaringan Komputer}

Menurut Irawan (2007) Jaringan komputer adalah sebuah kumpulan komputer, printer dan peralatan lainnya yang terhubung dalam satu kesatuan. Informasi dan data bergerak melalui kabel-kabel atau tanpa kabel sehingga memungkinkan pengguna jaringan komputer dapat saling bertukar dokumen dan data, mencetak pada printer yang sama dan bersama-sama menggunakan hardware/software yang terhubung dengan jaringan.

\subsection{Router}

Router adalah sebuah perangkat yang berguna untuk meneruskan paket-paket antara dua atau lebih jaringan. Router bekerja pada lapisan network (layer 3) menurut model referensi Open System Interconnection (OSI) atau lapisan internet pada model referensi TCP/IP (Tanenbaum, 2003).

\subsection{Storage Data}

Penyimpanan data komputer mengacu pada komponen komputer dan media perekaman yang mempertahankan data digital. Penyimpanan data merupakan salah satu fungsi inti dan komponen fundamental dari komputer menggunakan flashdisk dan hardisk sebagai penyimpanan primary dan secondary. 


\subsection{Perancangan Sistem}

Pada implementasi Samba server dapat digunakan pada sebuah jaringan local Area Network (LAN). Skema jaringan LAN dapat dilihat pada Gambar 1

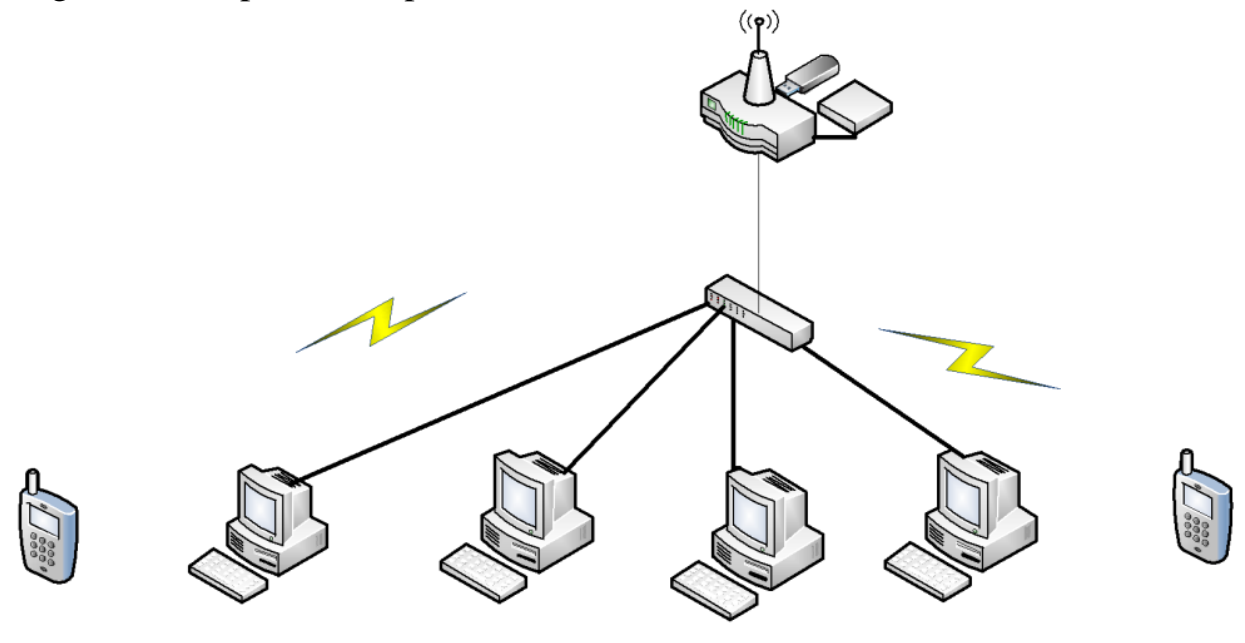

Gambar 1. Skema Jaringan Router

Dari skema jaringan router pada Gambar 1 dapat dijelaskan pada sebuah Router dikoneksikan terhadap satu buah Switch dengan network yang sama, smartphone terkoneksi pada jaringan Wireless. Dalam komputasi, file server adalah sebuah komputer terpasang ke jaringan yang memiliki tujuan utama memberikan lokasi untuk akses disk bersama namun dalam kasus ini router yang mengganti peranan komputer file server sebagai penyimpanan bersama file komputer (seperti dokumen, file suara, foto, film, gambar, database, dan lain-lain .) yang dapat diakses oleh workstation yang melekat pada jaringan router.

Istilah server menyoroti peranan mesin dalam client server skema, di mana klien workstation menggunakan penyimpanan. Sebuah file server tidak dimaksudkan untuk melakukan tugas-tugas komputasi, dan tidak menjalankan program atas nama client. Hal ini dirancang terutama untuk memungkinkan penyimpanan dan pengambilan data.

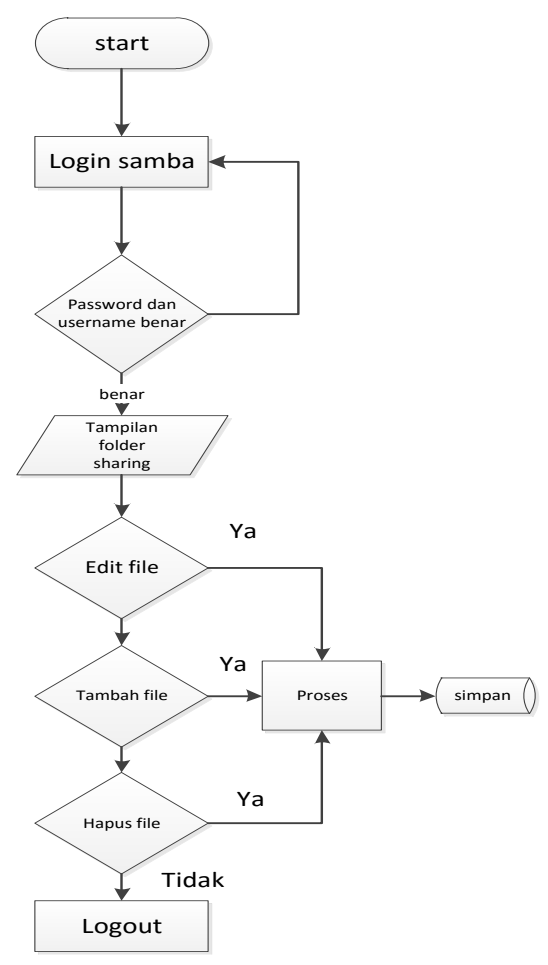


Gambar 2. Flowchart sistem

Gambar 2 merupakan flowchart sistem halaman admin hanya bisa diakses oleh admin. Untuk mengakses file username dan password di sesuaikan oleh administrator. Jika username dan password sesuai, maka user dapat mengakses file yang ada pada drive yang tersedia, namun jika proses gagal maka user tidak bisa mengakses file dan kembali memasukan username dan password. user dapat mengakses, mengedit, menambah, menghapus sesuai kebutuhan dan ketentuan yang di berikan oleh administrator.

\section{Hasil dan Pembahasan}

\subsection{Pengujian Kinerja Jaringan}

Pada pengujian kinerja jaringan ini akan dilakukan pengujian pengiriman dan penerimaan data memanfaatkan koneksi kabel LAN dan wireless sebagai jalur distribusi data router dengan firmware openwrt. Pengujian download dan upload melalui kabel LAN Table 1 merupakan hasil pengukuran dengan stopwatch waktu yang diperlukan mengirim data yang telah ditentukan

Tabel 1. Data pengujian waktu dengan kabel LAN

\begin{tabular}{|c|c|c|c|c|}
\hline \multirow[t]{2}{*}{ No } & \multirow[t]{2}{*}{ Nama File } & \multirow{2}{*}{$\begin{array}{l}\text { Ukuran } \\
\text { File }\end{array}$} & \multicolumn{2}{|l|}{ Waktu (s) } \\
\hline & & & Down-load & $\begin{array}{l}\text { Up- } \\
\text { load }\end{array}$ \\
\hline 1 & Foto.jpg & $3 \mathrm{MB}$ & 3.5 & 4.2 \\
\hline 2 & Mp3 & $4 \mathrm{MB}$ & 5.3 & 5.1 \\
\hline 3 & PDF & $5 \mathrm{MB}$ & 5.9 & 7.0 \\
\hline 4 & Word & $10 \mathrm{MB}$ & 6.1 & 12.9 \\
\hline 5 & MiPhoneflash.exe & $20 \mathrm{MB}$ & 7.4 & 14.1 \\
\hline 6 & MiSetup2.exe & $30 \mathrm{MB}$ & 8.6 & 14.9 \\
\hline 7 & Kies3Setup.exe & $40 \mathrm{MB}$ & 9.5 & 15.6 \\
\hline 8 & Ultra edit.exe & $50 \mathrm{MB}$ & 10.2 & 19.7 \\
\hline 9 & opnt37.mp4 & $100 \mathrm{MB}$ & 11.9 & 22.7 \\
\hline 10 & HaikS224INDO.mkv & $110 \mathrm{MB}$ & 13.5 & 39.4 \\
\hline 11 & HaikS225.END.mp4 & $120 \mathrm{MB}$ & 16.7 & 46.5 \\
\hline 12 & HaikS222INDO.mp4 & $130 \mathrm{MB}$ & 18.5 & 63.4 \\
\hline 13 & Naruto471.1080p.mp4 & $140 \mathrm{MB}$ & 20.1 & 71.9 \\
\hline 14 & jdkwindowsx64.exe & $200 \mathrm{MB}$ & 22.0 & 95.3 \\
\hline 15 & BlueStacks2.exe & $250 \mathrm{MB}$ & 24.4 & 152.9 \\
\hline 16 & Memu-Setup.exe & $300 \mathrm{MB}$ & 28.9 & 219.7 \\
\hline 17 & Central.Intel 480p.mkv & $350 \mathrm{MB}$ & 30.1 & 273.0 \\
\hline 18 & Wrong Turn 5.480p.mkv & $400 \mathrm{MB}$ & 38.3 & 347.3 \\
\hline 19 & Deadpool.480p.mkv & $450 \mathrm{MB}$ & 40.8 & 366.0 \\
\hline 20 & ROM advan S4A.rar & $500 \mathrm{MB}$ & 49.4 & 380.4 \\
\hline 21 & ROMSTOCK R1001.rar & $550 \mathrm{MB}$ & 59.6 & 421.5 \\
\hline 22 & Counter strike.zip & $600 \mathrm{MB}$ & 61.4 & 450.9 \\
\hline 23 & Deadpool.HDCAM.mp4 & $650 \mathrm{MB}$ & 79.1 & 465.2 \\
\hline 24 & Victor.Frank720p.mkv & $700 \mathrm{MB}$ & 99.9 & 490.1 \\
\hline 25 & Counter strike v7.exe & $750 \mathrm{MB}$ & 105.1 & 515.9 \\
\hline 26 & CATIA-V5R16.zip & $800 \mathrm{MB}$ & 121.9 & 529.2 \\
\hline 27 & RomRedmi3Unbrick.zip & $850 \mathrm{MB}$ & 149.5 & 550.2 \\
\hline 28 & miui_HM3_6.5_5.1.zip & $900 \mathrm{MB}$ & 160.2 & 583.2 \\
\hline 29 & Office2016.64.ISO & $950 \mathrm{MB}$ & 180.7 & 629.1 \\
\hline 30 & Spectre.2015.720p.rar & 1GB & 210.5 & 685.4 \\
\hline
\end{tabular}

Pengujian download dan upload melalui wireless hotspot Tabel 2 merupakan hasil pengukuran dengan stopwatch waktu yang diperlukan mengirim data yang telah ditentukan dapat dilihat pada Tabel 2. Dengan uji coba 1 client dengan besar kapasitas file yang telah di tentukan.

Tabel 2. Data pengujian waktu dengan wireless

\begin{tabular}{|c|c|c|c|c|}
\hline \multirow[t]{2}{*}{ No } & \multirow[t]{2}{*}{ Nama File } & \multirow[t]{2}{*}{$\begin{array}{l}\text { Ukuran } \\
\text { File }\end{array}$} & \multicolumn{2}{|c|}{$\begin{array}{ll}\text { Kecepatan } & \text { transfer } \\
\text { rate }(\text { Kbps }) & \end{array}$} \\
\hline & & & $\begin{array}{l}\text { Down- } \\
\text { load }\end{array}$ & Upload \\
\hline 1 & Foto.jpg & $3 \mathrm{MB}$ & 1000 & 750 \\
\hline 2 & Mp3 & $4 \mathrm{MB}$ & 800 & 800 \\
\hline 3 & PDF & $5 \mathrm{MB}$ & 833 & 714 \\
\hline 4 & Word & $10 \mathrm{MB}$ & 1667 & 909 \\
\hline 5 & MiPhoneflash.exe & $20 \mathrm{MB}$ & 2857 & 1667 \\
\hline 6 & MiSetup2.exe & $30 \mathrm{MB}$ & 3333 & 2308 \\
\hline 7 & Kies3Setup.exe & $40 \mathrm{MB}$ & 4444 & 2857 \\
\hline 8 & Ultra edit.exe & $50 \mathrm{MB}$ & 5000 & 2941 \\
\hline 9 & opnt37.mp4 & $100 \mathrm{MB}$ & 8333 & 4167 \\
\hline 10 & HaikS224INDO.mkv & $110 \mathrm{MB}$ & 8462 & 3667 \\
\hline 11 & HaikS225.END.mp4 & $120 \mathrm{MB}$ & 7059 & 2609 \\
\hline
\end{tabular}




\begin{tabular}{|r|l|r|r|r|}
\hline 12 & HaikS222INDO.mp4 & $130 \mathrm{MB}$ & 7222 & 2167 \\
\hline 13 & Naruto471.1080p.mp4 & $140 \mathrm{MB}$ & 7000 & 1972 \\
\hline 14 & jdkwindowsx64.exe & $200 \mathrm{MB}$ & 9091 & 2439 \\
\hline 15 & BlueStacks2.exe & $250 \mathrm{MB}$ & 10417 & 2717 \\
\hline 16 & Memu-Setup.exe & $300 \mathrm{MB}$ & 10345 & 1685 \\
\hline 17 & Central.Intel 480p.mkv & $350 \mathrm{MB}$ & 11667 & 1944 \\
\hline 18 & Wrong Turn 5.480p.mkv & $400 \mathrm{MB}$ & 10526 & 1914 \\
\hline 19 & Deadpool.480p.mkv & $450 \mathrm{MB}$ & 10976 & 1304 \\
\hline 20 & ROM advan S4A.rar & $500 \mathrm{MB}$ & 10204 & 1412 \\
\hline 21 & ROMSTOCK R1001.rar & $550 \mathrm{MB}$ & 9167 & 1482 \\
\hline 22 & Counter strike.zip & $600 \mathrm{MB}$ & 9836 & 1504 \\
\hline 23 & Deadpool.HDCAM.mp4 & $650 \mathrm{MB}$ & 8228 & 1505 \\
\hline 24 & Victor.Frank720p.mkv & $700 \mathrm{MB}$ & 7000 & 1570 \\
\hline 25 & Counter strike v7.exe & $750 \mathrm{MB}$ & 6522 & 1599 \\
\hline 26 & CATIA-V5R16.zip & $800 \mathrm{MB}$ & 6557 & 1633 \\
\hline 27 & RomRedmi3Unbrick.zip & $850 \mathrm{MB}$ & 5705 & 1638 \\
\hline 28 & miui_HM3_6.5_5.1.zip & $900 \mathrm{MB}$ & 5625 & 1664 \\
\hline 29 & Office2016.64.ISO & $950 \mathrm{MB}$ & 5249 & 1699 \\
\hline 30 & Spectre.2015.720p.rar & $1 \mathrm{~GB}$ & 4762 & 1637 \\
\hline
\end{tabular}

Pada pengujian kinerja QoS (quality of service) ini akan dilakukan pengujian pengiriman data memanfaatkan koneksi kabel LAN sebagai ujicoba sebanyak 20 user PC yang mengakses file distribusi data dari router dengan firmware openwrt secara simultan dan bertahap mulai dari 5 PC, 10PC, 15PC dan 20PC.

Tabel 3. Pengujian 5 user PC

\begin{tabular}{|c|c|c|c|c|}
\hline No PC & jenis file & besar file & $\begin{array}{c}\text { Persentase } \\
\text { keberhasilan }\end{array}$ & Status \\
\hline 1 & PDF & $10 \mathrm{MB}$ & $100 \%$ & Sukses \\
\hline 2 & PDF & $10 \mathrm{MB}$ & $100 \%$ & Sukses \\
\hline 3 & PDF & $10 \mathrm{MB}$ & $100 \%$ & Sukses \\
\hline 4 & PDF & $10 \mathrm{MB}$ & $100 \%$ & Sukses \\
\hline 5 & PDF & $10 \mathrm{MB}$ & $100 \%$ & Sukses \\
\hline
\end{tabular}

Pada pengujian Tabel 4 Dengan uji coba 10 user PC dengan besar kapasitas file yang telah di tentukan terjadi kegagalan beberapa PC dikarenakan bandwidth output data yang dimiliki router terbatas maka terjadi bottleneck.

Tabel 4. Pengujian 10 user PC

\begin{tabular}{|c|c|c|c|c|}
\hline No pc & Jenis file & $\begin{array}{c}\text { Besar } \\
\text { file }\end{array}$ & $\begin{array}{c}\text { Keberhasilan } \\
(\%)\end{array}$ & Status \\
\hline 1 & PDF & $10 \mathrm{MB}$ & $100 \%$ & Sukses \\
\hline 2 & PDF & $10 \mathrm{MB}$ & $100 \%$ & Sukses \\
\hline 3 & PDF & $10 \mathrm{MB}$ & $100 \%$ & Sukses \\
\hline 4 & PDF & $10 \mathrm{MB}$ & $100 \%$ & Sukses \\
\hline 5 & PDF & $10 \mathrm{MB}$ & $100 \%$ & Sukses \\
\hline 6 & PDF & $10 \mathrm{MB}$ & $100 \%$ & Sukses \\
\hline 7 & PDF & $10 \mathrm{MB}$ & $100 \%$ & Sukses \\
\hline 8 & PDF & $10 \mathrm{MB}$ & $100 \%$ & Sukses \\
\hline 9 & PDF & $10 \mathrm{MB}$ & $70 \%$ & Gagal \\
\hline 10 & PDF & $10 \mathrm{MB}$ & $50 \%$ & Gagal \\
\hline
\end{tabular}

Tabel 5. Pengujian 15 user PC

\begin{tabular}{|c|c|c|c|c|}
\hline No PC & $\begin{array}{c}\text { jenis } \\
\text { file }\end{array}$ & besar file & $\begin{array}{c}\text { Persentase } \\
\text { keberhasilan }\end{array}$ & Status \\
\hline 1 & PDF & $10 \mathrm{MB}$ & $100 \%$ & Sukses \\
\hline 2 & PDF & $10 \mathrm{MB}$ & $89 \%$ & Gagal \\
\hline 3 & PDF & $10 \mathrm{MB}$ & $40 \%$ & Gagal \\
\hline 4 & PDF & $10 \mathrm{MB}$ & $100 \%$ & Sukses \\
\hline
\end{tabular}




\begin{tabular}{|c|c|c|c|c|}
5 & PDF & $10 \mathrm{MB}$ & $100 \%$ & Sukses \\
\hline 6 & PDF & $10 \mathrm{MB}$ & $100 \%$ & Sukses \\
\hline 7 & PDF & $10 \mathrm{MB}$ & $100 \%$ & Sukses \\
\hline 8 & PDF & $10 \mathrm{MB}$ & $100 \%$ & Sukses \\
\hline 9 & PDF & $10 \mathrm{MB}$ & $80 \%$ & Gagal \\
\hline 10 & PDF & $10 \mathrm{MB}$ & $50 \%$ & Gagal \\
\hline 11 & PDF & $10 \mathrm{MB}$ & $20 \%$ & Gagal \\
\hline 12 & PDF & $10 \mathrm{MB}$ & $100 \%$ & Sukses \\
\hline 13 & PDF & $10 \mathrm{MB}$ & $100 \%$ & Sukses \\
\hline 14 & PDF & $10 \mathrm{MB}$ & $10 \%$ & Gagal \\
\hline 15 & PDF & $10 \mathrm{MB}$ & $77 \%$ & Gagal \\
\hline
\end{tabular}

Tabel 6. Pengujian 20 user PC

\begin{tabular}{|c|c|c|c|c|}
\hline No PC & jenis file & besar file & $\begin{array}{c}\text { Persentase } \\
\text { keberhasilan }\end{array}$ & Status \\
\hline 1 & PDF & $10 \mathrm{MB}$ & $98 \%$ & Gagal \\
\hline 2 & PDF & $10 \mathrm{MB}$ & $49 \%$ & Gagal \\
\hline 3 & PDF & $10 \mathrm{MB}$ & $92 \%$ & Gagal \\
\hline 4 & PDF & $10 \mathrm{MB}$ & $100 \%$ & Sukses \\
\hline 5 & PDF & $10 \mathrm{MB}$ & $100 \%$ & Sukses \\
\hline 6 & PDF & $10 \mathrm{MB}$ & $72 \%$ & Gagal \\
\hline 7 & PDF & $10 \mathrm{MB}$ & $100 \%$ & Sukses \\
\hline 8 & PDF & $10 \mathrm{MB}$ & $86 \%$ & Gagal \\
\hline 9 & PDF & $10 \mathrm{MB}$ & $88 \%$ & Gagal \\
\hline 10 & PDF & $10 \mathrm{MB}$ & $69 \%$ & Gagal \\
\hline 11 & PDF & $10 \mathrm{MB}$ & $33 \%$ & Gagal \\
\hline 12 & PDF & $10 \mathrm{MB}$ & $100 \%$ & Sukses \\
\hline 13 & PDF & $10 \mathrm{MB}$ & $100 \%$ & Sukses \\
\hline 14 & PDF & $10 \mathrm{MB}$ & $71 \%$ & Gagal \\
\hline 15 & PDF & $10 \mathrm{MB}$ & $25 \%$ & Gagal \\
\hline 16 & PDF & $10 \mathrm{MB}$ & $100 \%$ & Sukses \\
\hline 17 & PDF & $10 \mathrm{MB}$ & $100 \%$ & Sukses \\
\hline 18 & PDF & $10 \mathrm{MB}$ & $11 \%$ & Gagal \\
\hline 19 & PDF & $10 \mathrm{MB}$ & $100 \%$ & Sukses \\
\hline 20 & PDF & $10 \mathrm{MB}$ & $100 \%$ & Sukses \\
\hline & & & & \\
\hline
\end{tabular}

Dari analisa Tabel 4, Tabel 5, Tabel 6, pengujian QoS (Quality of Service) yang telah di lakukan dari 5 PC, 10PC, 15PC dan 20PC dapat di simpulkan bahwa router bekerja dengan cukup baik, router dapat mengirim data dengan media kabel LAN walaupun terdapat kekurangan yaitu sedikitnya output data dalam pengiriman data mempengaruhi router mengakibatkan pengiriman data yang lambat dan sering terjadi faied connection pada saat pengiriman data ke $10,15,20$ user PC terjadi bottleneck, berbeda pada saat pengiriman data pada 5 user PC tidak mengalami failed connection. 


\section{Kesimpulan dan Saran}

\subsection{Kesimpulan}

Kesimpulan dari tugas akhir yang berjudul "Rekayasa router untuk penyimpanan data" adalah sebagai berikut:

1. Router dapat di rekayasa untuk menyimpanan data memanfaatkan jaringan wifi dan kabel LAN sesuai dengan yang di rencanakan.

2. Setelah melakukan konfigurasi pada router dapat di kendalikan dari jauh menggunakan komputer atau smartphone pada satu jaringan.

3. Router maksimal melakukan transfer data sebanyak 5 user PC lebih dari itu sering terjadi pengiriman failed connection

4. Dari persentase kegagalan pengiriman data terjadi secara acak tidak dapat di prediksi pada PC mana yang akan gagal mengiriman data

\subsection{Saran} berikut :

Dalam pelaksanaan tugas akhir ini, adapun beberapa saran yang dicantumkan adalah sebagai

1. Untuk melakukan transfer data di area jaringan lebih luas maka perlu dikembangkan skema jaringan yang diterapkan pada Router dan melakukan konfigurasi pada jaringan yang akan digunakan.

2. Penelitian kedepan diharapkan mampu membuat jaringan SAN dengan mekanisme transfer data secara dalam mencangkup area jaringan yang lebih meluas.

3. Lebih dikembangkan lagi baik dalam fitur maupun performa untuk melakukan hal-hal yang lebih besar lagi.

\section{DAFTAR PUSTAKA}

[1] Irawan, Budhi. 2007, Jaringan Komputer. Bandung : Graha Ilmu.

[2] Linuxconfig Admin. 2011. Bash Scripts To Scan And Monitor Network. www.linuxconfig.org.

[3] Lowe, D. 2008. Networking all-in-One Desk Reference For Dummie (4th edition). Hoboken : Wiley Publishing

[4] Tanenbaum, Andrew S. 2003. Computer Networks 4 edition. Prentice Hall.

[5] Wagito. 2007. Jaringan Komputer Berbasis Linux. Java Media. Yogyakarta.

[6] Wiki OpenWRT. 2011. TP-Link MR3020. Wiki.openwrt.org.

[7] Wagito. 2007. Jaringan Komputer, Teori dan Impelementasi Berbasis Linux. Yogyakarta : Gaya Media.

[8] Yuliardi, Rofiq. 2002. BASH Scripting Untuk Administrasi Sistem Linux : ElexMedia Komputindo. Jakarta. 